\title{
The MFL technique - Basic application for PT cable break detection in concrete structures
}

\author{
Martin Wilcke ${ }^{2}$, Andrei Walther ${ }^{1,2}$, Klaus Szielasko ${ }^{3}$, and Sargon Youssef ${ }^{3}$ \\ ${ }^{1}$ University of Applied Sciences, Potsdam \\ ${ }^{2}$ Kiwa GmbH, Berlin \\ ${ }^{3}$ Fraunhofer Institute for Non-Destructive Testing, Saarbrücken
}

\begin{abstract}
From the beginning of building techniques creating pre-stressed and accordingly post-tensioned concrete structures until the late 1980ies manufacturers and construction companies dealt with pre-stressing steel material vulnerable to stress corrosion cracking. Almost every load-bearing structure requires regular inspection on a mandatory basis. Due to knowledge of pre-stressed structural reinforcement susceptible to stress corrosion cracking being used during construction or visible damage alongside the tendon area arises the demand for detailed investigation of cracks within the post-tensioned steel elements. Even though the prestressed steel elements of a structure are not especially at risk for stress corrosion cracking by its manufacturing process, the natural deterioration of the building fabric and manifold eventual defects and failure during structure erection encourage the requirement for an inspection of their structural integrity at least within the most important load-bearing areas. Therefore needed investigations can be carried out by application of the nondestructive magnetic flux leakage measurement technique for single bar elements and stranded wire tendons even inside cladding tubes. This testing method is subject to successful research work for more than 30 years now and has proven its validated functionality with impressive results on a big number of investigated structures including bridge elements, truss beams and container components.Starting with the basic physical measurement principle of magnetic flux leakage for dipole-formation in the area of fractures of the magnetized pre-stressed steel elements this document presents the practical application possibilities and development history of the testing method.With the consecutively presented further development of the BetoFlux-System we can provide a piece of testing equipment which combines the advantages of a pure physical measurement principle with the economical requirements for an on-site-application to investigate prestressed reinforcing steel elements at an early stage prior to structural collapse hazards.
\end{abstract}

\footnotetext{
${ }^{*}$ Corresponding author: martin.wilcke@kiwa.de
} 


\section{Introduction}

Especially in the 1950s to the 1970s, many new buildings were built in the pre-stressed concrete construction. In particular, bridges, car-parks and prefabricated structural elements were made of prestressed concrete components. By installation of a preloaded stress level by means of high-strength steels, compressive stresses are generated in the concrete crosssection, which cause even after application of the external loads and effect of timedependent deformations, no or small excesses of concrete tensile strength. This allows crack-free tensile zones in the component cross-section, lower deflections, slim structures, larger spans and savings of slack reinforcing steel material.

By application of non-destructive material testing methods of the installed pre-stressing steel elements cracks or breakage conditions can be detected inside the structure without impairing the serviceability of the examined structure.

The energetic interaction of the testing system with the examination object is evaluated by utilizing the known physical dependencies or effects and transferred to a test statement([1]).

From the 1980s onwards, damage and sudden structural failure of pre-stressed concrete structures increased significantly (for example, 1980 Kongresshalle Berlin, 1985 Hallenbad Uster Schweiz, 1989 Fabrikhalle Mannheim, 2005 bridge component Lake View Bridge USA, see Fig. 1).

The causes of most known cases of damage are usually due to hydrogeninduced stress corrosion cracking (SCC) of pre-stressing steel components. Natural concrete deterioration behaviour of concrete structures like carbonation or the intrusion of high chloride contents towards the reinforcing elements causing pit hole corrosion due to formation of small anodic areas on the steel surfacce lead to severe damage situations when left disregarded for a longer period of time.

The SCC is a process in which corrosion and cracking of a metal occur as a result of internal or applied tensile stresses. This is favored by insufficient or incorrect compression of the ducts, notches in the pre-stressing steel, low concrete cover, defective sealing and inadequate drainage. The specific threat of the SCC is that the corrosion process is not visible from the

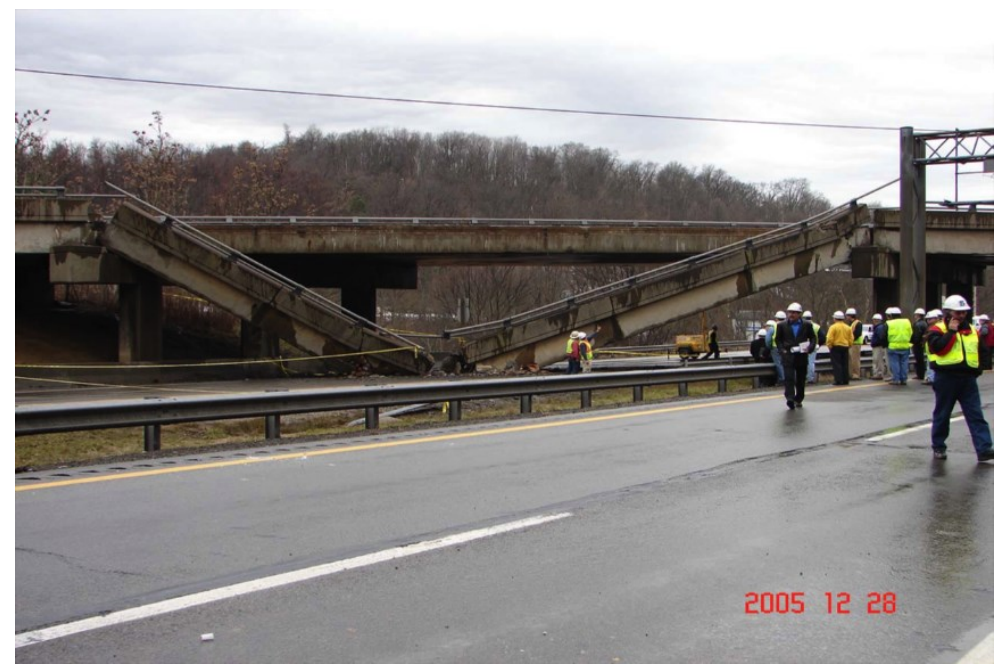

Figure 1. overnight collapse of prefabricated box girder elements Lake View Bridge, PA USA, Dez. 2005 
outside, that it runs with little or even no deformation and that a sudden failure might occur without prior notice.

Fracture conditions in pre-stressing steel elements usually do not initially lead to any externally perceptible changes to the structure. If cracks and fractures of tendons accompanied by strong deformations occur on the structure, then at least the serviceability is generally no longer given and a costly repair, if at all possible, is the mandatory result. To ensure the stability of pre-stressed concrete structures, the socalled "crack-before-break" criterion has to be proven by an inspecting engineer for structural analysis.

By regularly inspecting pre-stressed reinforced concrete structures, potential hazards can be detected early and thereby the need for maintenance may be identified to ensure the stability, serviceability and durability of economically significant infrastructure.

\section{Development process of the the testing method}

The beginning of simple applications for the investigation of existing structures in practice took place i.a. already in the late 1989s through the work of Hillemeier and
Flohrer in the large-scale investigations of cattle-shed roofs in Germany. By means of line measurements on pre-fabricated prestressed concrete girders, individual tendons inside the lower flange of I-beams of the ceiling constructions were tested and fractures were successfully detected [3].

In the further course of the research work, the next development step was carried out for the automatic recording of the measurement results for the individual sensor elements in order to be able to carry out a later detailed evaluation on the PC, see also Fig. 2.

Continuous research an development at Technical University in Berlin on imaging test methods with practical relevance by exploiting the remanence magnetism of the pre-stressed reinforcement made it possible to measure areas using larger equipment technology from the mid-2000s, see Fig. 3. Especially with the MobiRem-Device it is possible to investigate a highway bridge for fractures in the transverse tendons of the bridge deck within one single night ([5] and [6]).

Thanks to the newly developed BetoFlux-System, it is possible to carry out imaging line measurements without external power supply and with wireless transmission of measured values for

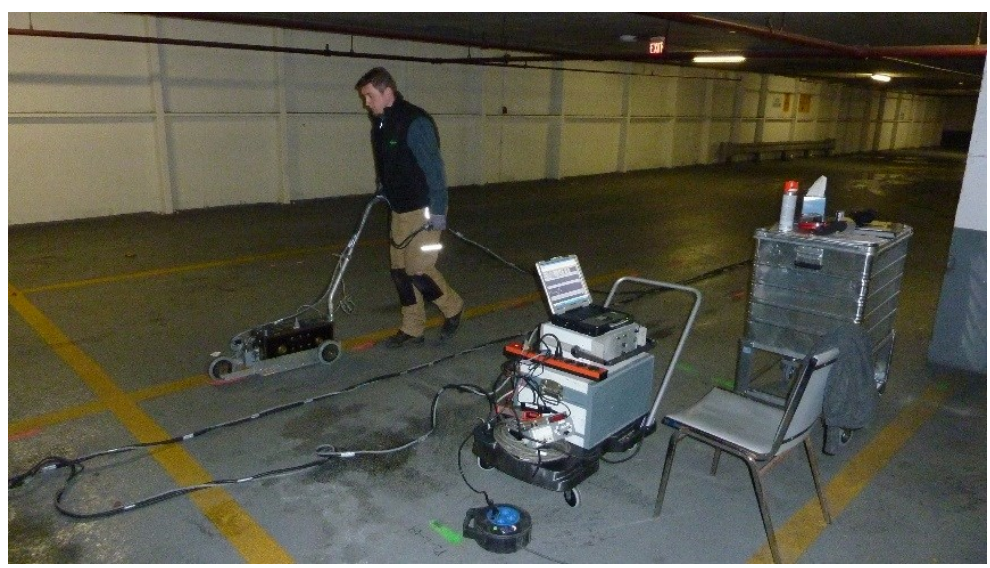

Figure 2. Line-Scanning-System (Electromagnet, wired signal transmission) 


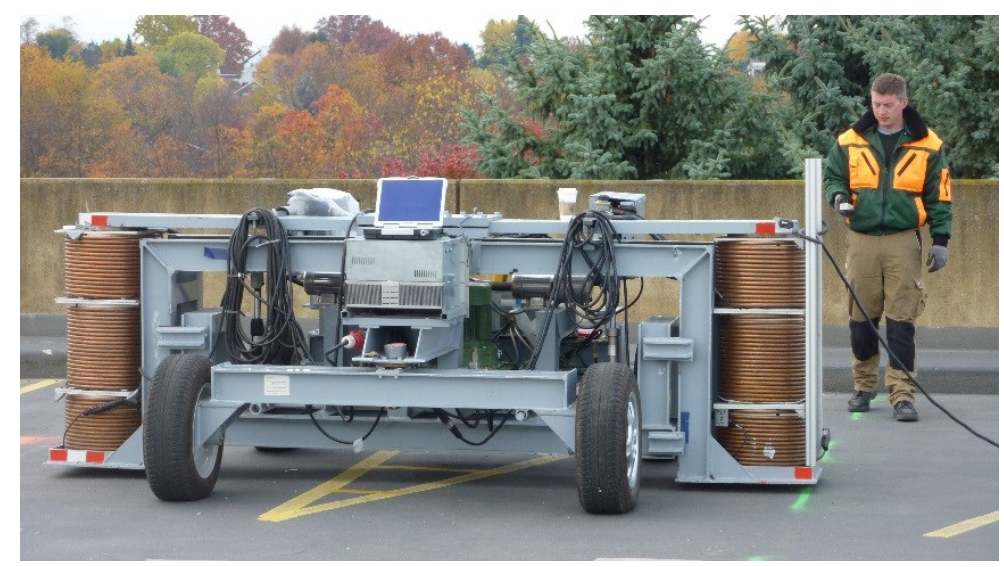

Figure 3. Line-Scanning-System (Large Scale Electromagnet, Testing direction rectangular to Tendon axis)

recording at the measuring computer, Fig. 4.

The testing device contains i.a. a sensor line oriented perpendicular to the test direction which enables the testing engineer to generate a surface-like resolution of the test section. The measurements are made in the active magnetic field without previous magnetization steps.

\section{Principle of measurement}

The magnetic leakage flux method is in principle very well suited for the detection of crack-like defects in ferromagnetic materials. This method is used in both the remanent and active magnetic fields in nondestructive testing for fracture location in pre-stressed concrete structures in civil engineering ([1] and [2]).
The method relies on a physical effect which is also exploited in magnetic particle inspection, e.g. is widespread and standardized in the steel processing industries. At sharp-edged interruptions of the surface of a component, when an external magnetic field is applied, additional magnetic dipoles, which cause a stray magnetic field near the surface, are formed, see Fig. 5. With the help of electric or permanent magnets in combination with the ferromagnetic pre-stressing steel, a magnetic circuit is closed.

Due to the magnetic permeability of the concrete cover and the air gap, the magnetic field is attenuated by the distance to the prestressing steel with the reciprocal of the distance square. This must be considered in the form of a sufficiently strong magnetization.

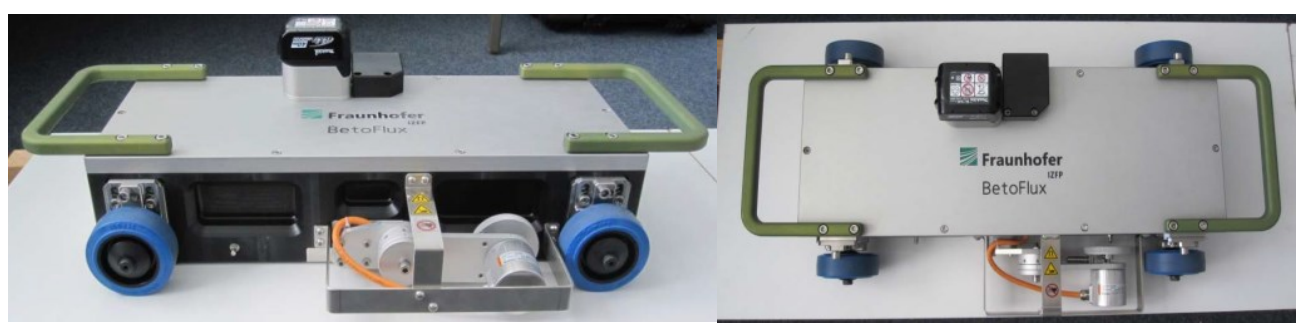

Figure 4. BetoFlux-System (wireless Line-Scanning-SystemTesting using permanent magnets, Testing direction along tendon axis) 


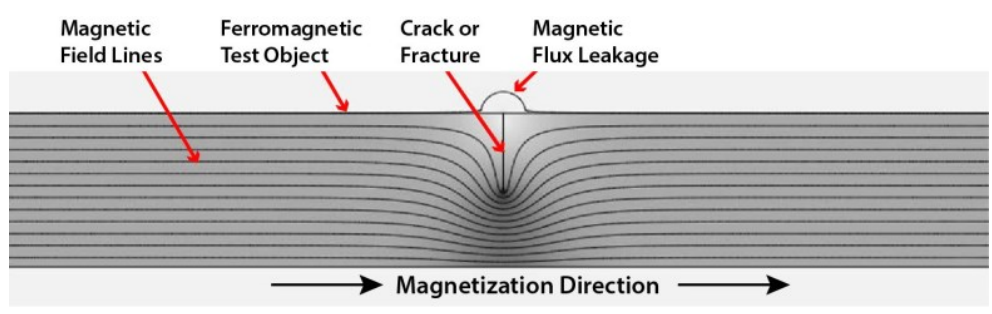

Figure 5. Principle course of the magnetic field at a crack in a magnetized steel component

With increasing distance from the damaged pre-stressing steel, the magnetic stray field is attenuated and blurred, whereby a correspondingly strong magnetization is not sufficient to detect any adjacent errors. Rather, the combination of magnetization strength, dimensions of the yoke and the distance to the pre-stressing steel in the design of the magnetization is crucial for the possible fault detection. In principle, both the component tangential to the surface (axial) of the magnetic field vector and the component normal to the surface (transversal) can be used for detection of fracture-like conditions within the steel element. Fig. 6 shows the qualitative course of the normal component over a fixed distance with the undamaged pre-stressing steel (left) and with the damaged pre-stressing steel (right).

A new magnetic pole pair is formed around defaulted area in the pre-stressing steel, exactly above the fracture-like point the normal component of the stray magnetic field is zero due to the pole change. Changes in magnetic flux due to stray fields

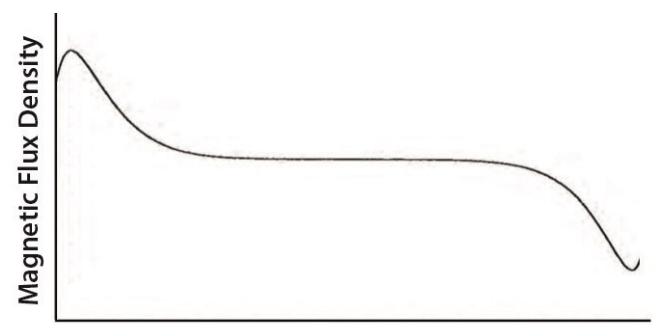

Distance / measuring Length at defects and separation cracks can be detected by Hall sensors and visualized in the result display. By utilizing the Hall effect, a voltage induction occurs in the case of a magnetic field change in the current-carrying conductor loop inside the sensor element.

\section{Test method for magnetic flux leakage measurement for break detection in pre- stressing steel elements}

With the non-destructive method based on the magnetic stray field measurement qualitative statements can be made about the state of built-up tendons in structures and, if necessary, fractures in the PT tendons can be localized. The bondforming type of pre-stressing steels is arbitrary ([3] and [4]). Both pre-stressing steel fractures in immediate bond (steel is already pre-stressed during concreting) and subsequent bonding (post-tensioning of steel after concrete hardening) can be

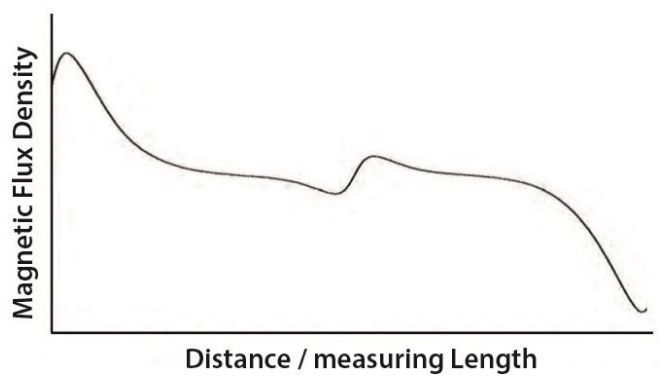

Figure 6. Course of the normal component (transversal to the tendon axis) between the magnetic poles left without and right with error [1] 
determined. Even with touch contact of both fracture edges a location is possible.

Since this is a relatively quick nondestructive testing method, the structures do not need to be completely closed for inspection or the concrete cover over the tendons does not have to be removed over a large area ([7]).

Common to all magnetic methods is the fact that the pre-stressed steel reinforcement can be magnetized by an external magnetic field and fractures can be located by detecting the stray field in the remanent state or by measuring the active stray field. At breaks, a pole change occurs in the magnetic flux density, which can then be recognized in the flux leakage diagram ([1] and ([6]). A magnetic test system is guided over the concrete component surface via the tendon to be examined. Magnetic stray fields form at break points of individual tension wires, which are also observed at break points of broken bar magnets and are referred to a dipole formation at break points, see Fig. 7 left.

At a point of breakage, a magnetic north pole $(\mathrm{N})$ and a south magnetic pole $(\mathrm{S})$ are located close to each other. The measurement signal shows a characteristic course, as shown in Fig. 7 right. Between the two poles (extreme values) is the inflection point of the signal curve, which indicates exactly the middle of the break point.

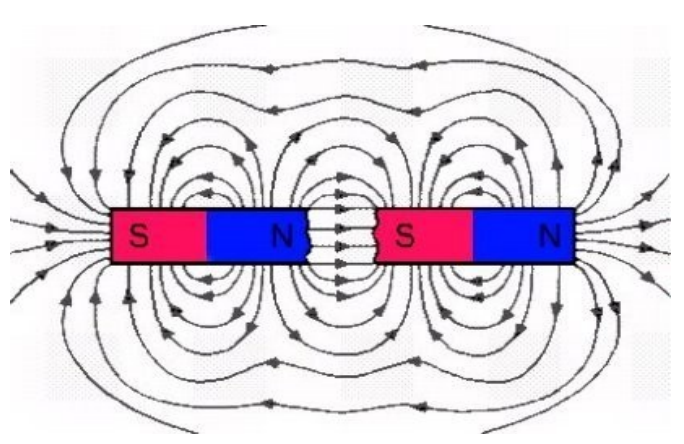

\section{Device development BetoFlux}

As early as 2007, a first BetoFlux test system was designed at the Fraunhofer IZFP. This with the premise for the detection of corrosion damage to prestressed concrete pylons by measurements along the circumferential surface of a specific height level.

The new BetoFlux system presented here is to be used for investigations on all conventional PT tendons in concrete structures of civil engineering.

On the one hand, this means larger diameters and, on the other, significantly higher concrete coverages of the prestressed steel elements to be tested. Due to the limited accessibility on the test sites to larger reinforced concrete structures, there is a need for a testing system that enables the mobile and easy-to-use use of the magnetic leakage flux method. In addition to the simple handling, selection and arrangement of suitable sensors, the special challenge lies in the design of a testing technology with the lowest possible power consumption for mobile use. To optimize the operational mobility of the BetoFluxSystem, permanent magnets are used in combination with a yoke as a flux bridge, instead of an electromagnet.

Fig. 8 shows the course of the magnetic field lines in the pre-stressing steel both in the undamaged (left) and in the damaged (right) case.

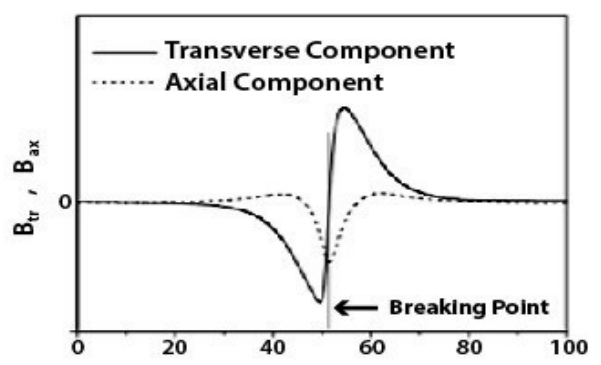

Figure 7. Left: magnetic stray field, right: course of the measuring signal separated according to directional components 

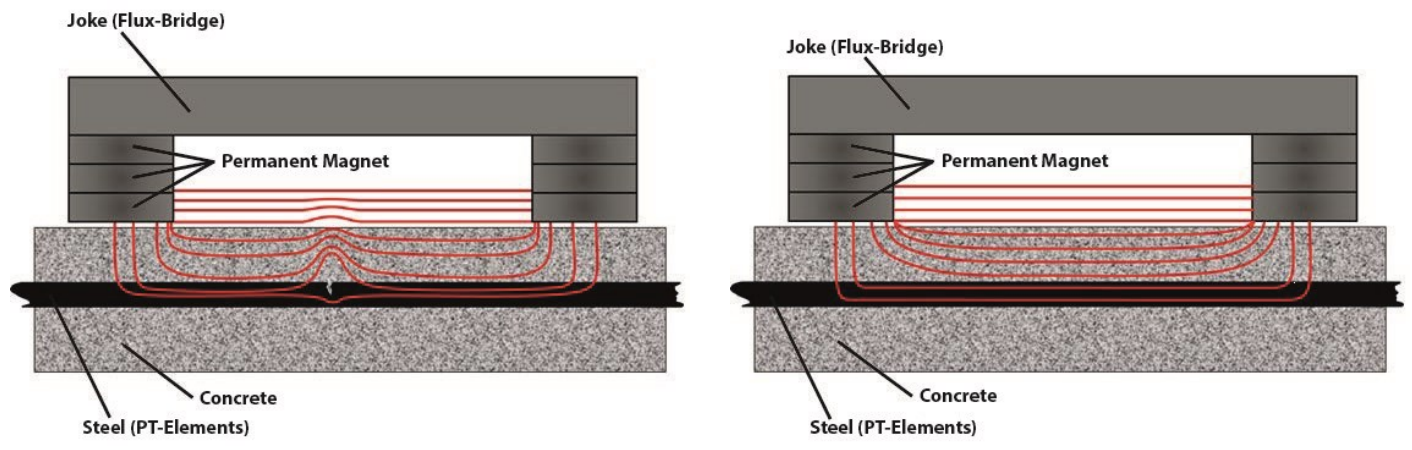

Figure 8. Field line course on undamaged (left) and damaged (right) pre-stressing steel

For measuring the magnetic flux density Hall-Sensor elements are used, which are characterized by a sufficient sensitivity and a site-specific robustness. The measuring device is equipped with a Hall-Sensor Line-Array with 80 probes total. The signals are displayed as a function of distance on a measuring computer via WiFi-link and stored for documentation purpose. The assignment of fracture-line signals to the possible suspected location is always given. The raw signal of the measurement reading can be mapped as a black and white graduated translation image over the measuring distance.

By going through a multilevel development cooperation from the definition of performance parameters for the practical application in the structure investigation over the computer-aided simulation and test measurements at different realistic laboratory configurations up to the optimization of software-side result representation respectively evaluation algorithms, a construction site suitable test system was developed, which can cover the standard constructions in prestressed concrete construction.

On reproducibly documented test scenarios are i.a. complete fractures of mono-strands with a diameter of $8 \mathrm{~mm}$ in a sensor lift of $15 \mathrm{~cm}$ depth are clearly detectable, see Fig. 9.

Using an individually constructed rail system uniformly guided measurements on vertical side surfaces and horizontal undersides of test objects are possible, see Fig. 10.
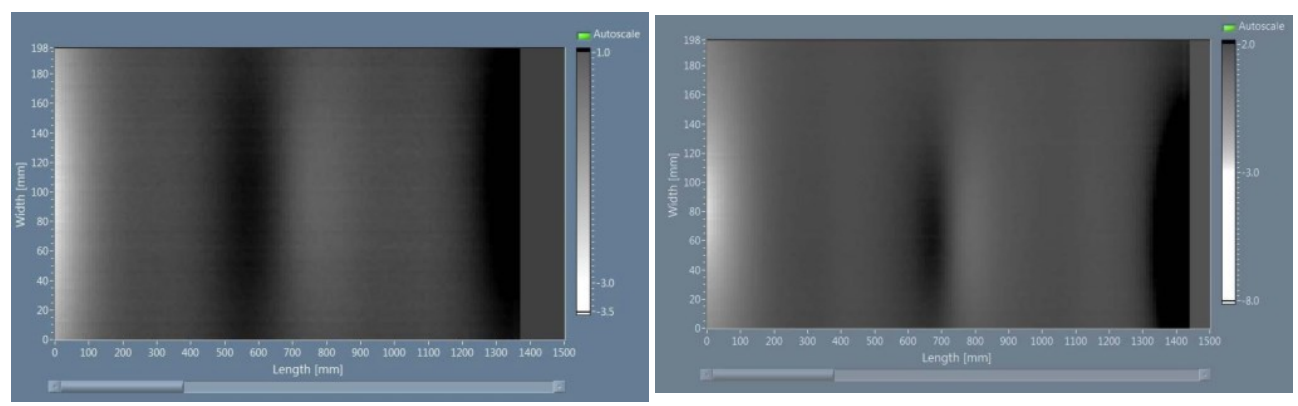

Figure 9. Clearly detectable complete fracture of a mono-strand pre-stressing steel tendon in the real test scenario, left $10 \mathrm{~cm}$, right $15 \mathrm{~cm}$ cover/sensor lift 

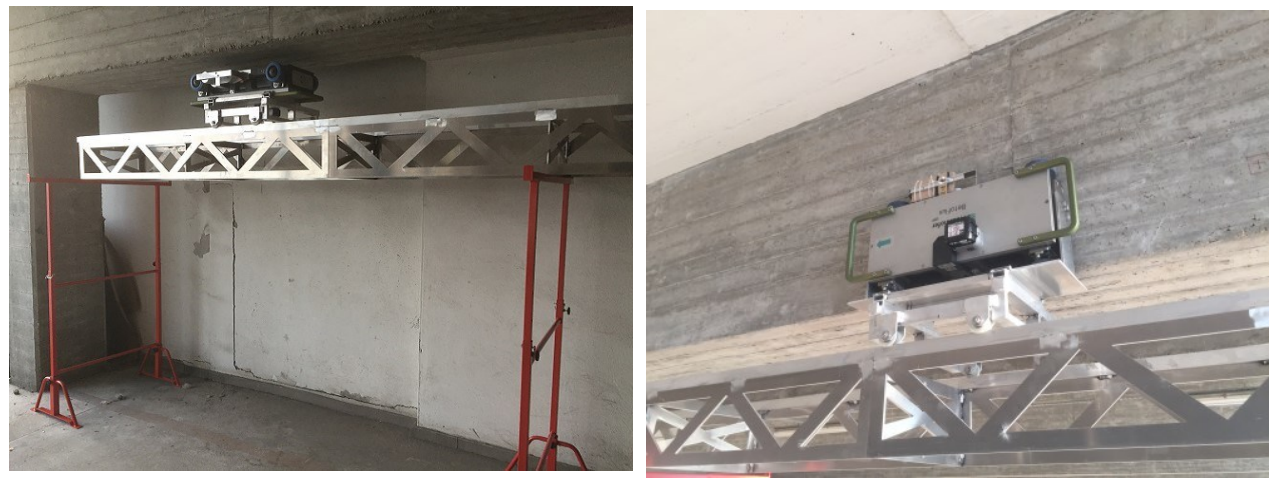

Figure 10. Testing system BetoFlux for locating pre-stressing steel fractures on rail system

\section{Application example}

The authors examined various structures in pre-stressed concrete construction to detect fractures in the PT elements using nondestructive magnetic flux leakage measurement methods. A representative application example for the newly developed BetoFlux system is shown in the following $([10])$. The girders of a ceiling construction of a two-storey hall building on the ground and first floor were manufactured as pre-stressed concrete beams in in-situ concrete construction. Post-tensioning of the beams was carried out in subsequent composite of the tendon bundles guided in pressed metallic ducts, see Fig. 11. On the ground floor there is a car repair shop and a tire warehouse. The first floor is used as a parking deck.

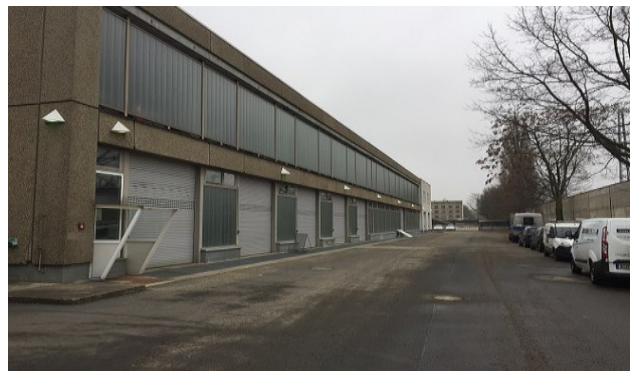

A static report prepared in advance by the structural engineer clarified the necessity of further state determinations via measurement and testing for the assessment of permanent stability of the building construction. Among other things, the condition of the PT tendons in the prestressed concrete girders should serve as a basis for the decision in static model calculations.

In the course of the previous inspection for reconnaissance and coordination with the client specifications were made regarding the construction freedom and caused changes in the cable management. Girders hidden behind massive suspended ceilings and cladding were not examined after consultation with the structural engineer.

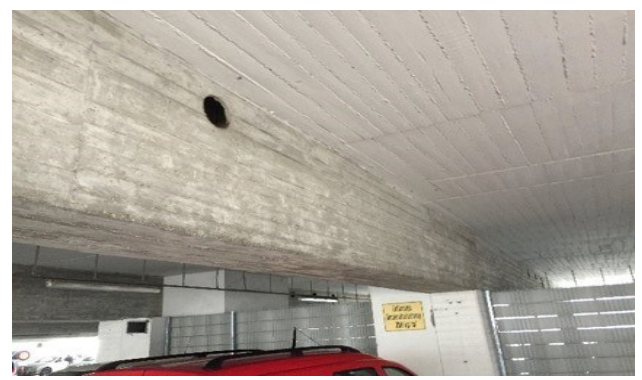

Figure 11. Left: magnetic stray field, right: course of the measuring signal separated according to directional components 

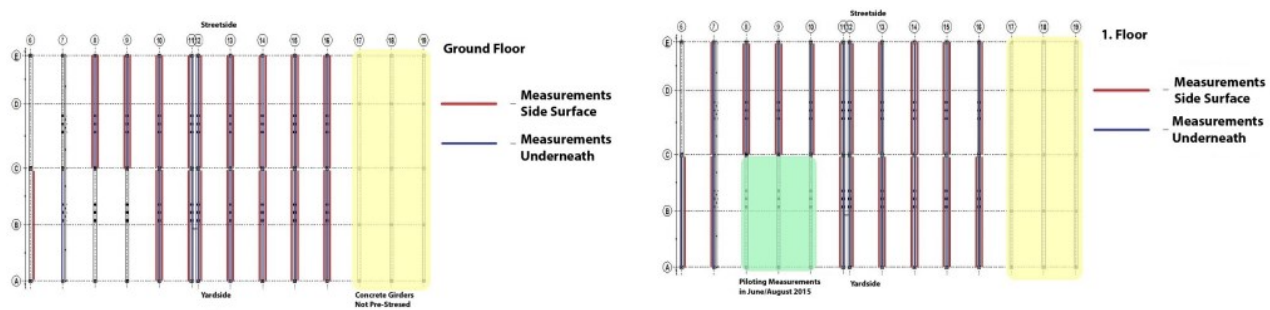

Figure 12. Schematic representation of the test plan for the investigations on pre-stressing steel fractures by means of MFL measurements

A graphical documentation of the measuring areas, taking into account the accessibility, is shown in Fig. 12. For the measurements on the girder surface supporting structures of different construction types were used.

Because of the only approximately known tendon position, radar examinations were carried out in order to determine the measuring lines for the test system exactly along the tendon axes for the preparation and to ensure result quality of the flux leakage measurements.

Exemplary measurement results from testing on an underneath surface of a girder are given in Fig. 13. During multi-step interpretation of testing results the slack reinforcing steel stirrups transversely to measurement direction as well as along the measuring direction mounted metallic parts of the duct support could be identified. A clear emergence of a magnetic north pole and a magnetic south pole at probably both ends of the reflector (enlarged image section) can be described.

Fig. 14 below shows exemplary measurement results of a girder side surface. Transversely to the direction of measurement the slack reinforcing steel stirrups could be identified.

A total of about 900 meters of measurements on the side surfaces and about 1200 meters on the undersides were carried out on 20 pre-stressed concrete girders in the hall construction on the ground and 1st floor. By partially blocking individual partial areas, the building operation and the daily use of the parking level could be maintained. The technical measurement investigations took about 10 days with time interruptions.

The evaluation of all measurement data of all pre-stressed concrete girders of the hall construction revealed no fracture-like signals, which indicated breaks in the PT tendons.

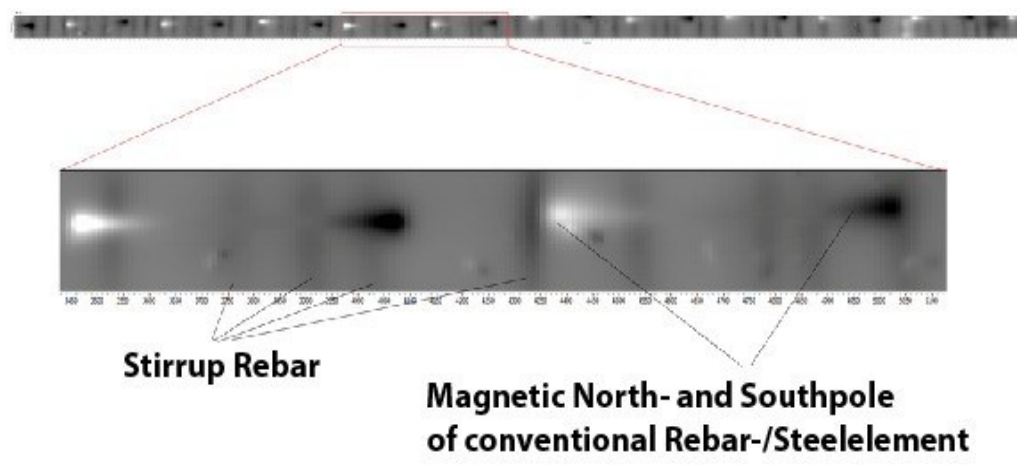

Figure 13. Section of a measuring line underneath of a pre-stressed concrete girder 


\section{Сан .}

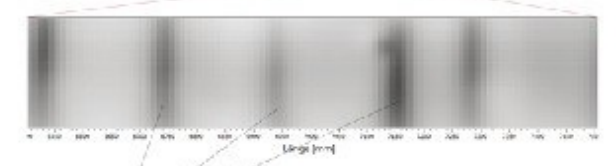

Magnetic North-and Southpole

of conventional Rebar-/Steelelement

Figure 14. Section of a measuring line on the vertical side surface of a pre-stressed concrete girder

\section{Conclusion}

Statements about the condition of prestressed steel reinforcements are not only important for ensuring the stability and usability of structures under known load levels but also for the conversion and renovation of structures. With the prestressing steel breakage detection based on MFL technique it is possible to make nondestructive test statements. It is essential to coordinate with the client regarding the possibilities and limits of the respective examination task. A test plan has to be developed which clarifies the exact scope of the test and the required or existing accessibility.

The engineering knowledge about the structural design is obligational, so that the measurement results can be evaluated correctly. Prior to interpration and evaluation of measuremant readings it is mandatory to check the construction details and the most likely endangered spots of the structure to be investigated.

Main criterion for fracture indication on pre-stressed steel reinforcements is a close change in magnetic poles in line of the PTElement. The ususal reading obtained by crossing an overlapping rebar is significantly different so that probabilities of misinterpretation of single signals are reduced to a reasonable minimum.

The MFL technique pre-stressing steel break location is a comparatively fast testing method which enables imaging based on-site evaluation of suspected spots for fracture locations in PT tendons. Within the almost 30-year development and application history of magnetic prestressing steel breakage detection, substantial process optimization was made by the in part independently working teams. As a non-destructive testing method widely recognized and used by experts, the magnetic pre-stressing steel breakage detection is on the verge of becoming the acknowledged rule of technology in prestressed concrete structure testing.

The Subcommittee Magnetic Processes for Pre-stressing Steel Breakage Detection of the Technical Committee for NDT in Construction of the German Society for Non-Destructive Testing deals with the further development and dissemination of the procedure. A position paper with further explanations on the process of pre-stressing steel breakage detection was published at the end of 2017([9]). Future developments could focus the application-oriented research on the quantitative determination of the exact number of fractures of cracked strands, the optimized automation of the evaluation of results and new devices for achieving greater depths of detection.

\section{References}

[1] Walther, A., Vergleichende Signalinterpretation von Spannstahlbrüchen im remanenten und aktiven magnetischen Streufeld (Dissertation, Technical University Berlin, 2012) 
[2] Youssef S., Szielasko K., Birringer R., Kurz, J, Sourkov A., Pushkarev S., BetoFlux: Mobiles StreuflussPrüfsystem zur Detektion von Korrosionsschäden an Spannbetonmasten (Annual Convention DGzfP, 2014)

[3] Hillemeier, B., Flohrer, C. und Schaab, A. , Zerstörungsfreie Ortung von Spannstahlbrüchen in Spannbeton-Deckenträgern (Betonund Stahlbetonbau 84, 1989)

[4] Sawade, G., Anwendung der Methode der magnetischen Streufeldmessung zur Ortung von Spanndrahtbrüchen (DGZfP-report volume 66, 1999)

[5] Scheel, H. , Spannstahlbruchortung von Spannbetonbauteilen mit nachträglichen Verbund unter Ausnutzung des Remanenzmagnetismus (Dissertation, Technical University Berlin, 1997)

[6] Pak, Ch. I , Optimierung des Remanenzmagnetismus-Verfahrens zur Stahlbruchortung in Bauwerken Theoretische Weiterentwicklung (Dissertation, Technical University Berlin, 2010)

[7] Hillemeier, B., Walther, A., BetoFlux:Schnelle zerstörungsfreie Ortung von Spannstahlrissen in Querspanngliedern Spannbetonbrücken von Convention DGzfP, 2007)

[8] Hillemeier B., Taffe A., Walther A. , Verifizierung moderner zerstörungsfreier Prüfverfahren an einem Abbruchbauwerk Zustandsermittlung, Untersuchung und Verifizierung von Messergebnissen an einem 45 Jahre alten Spannbetonbauwerk (Beton- und Stahlbetonbau 105, 2010)

[9] TSC Magnetic Processes for PreStressing Steel Breakage Detection, Position Paper - Magnetic Methods for PT Steel Breakage Detection (DGZfP e.V., TC NDT Civil Engineering, 2017)

[10] Walther A., Wilcke M., Brossmann N. , Zerstörungsfreies Untersuchen von Spannbetonbauteilen

(Der 